REVIEW

\title{
Sudden infant death syndrome: a critical review of approaches to research
}

\section{P N Goldwater}

Arch Dis Child 2003;88:1095-1100

This review explores the various research approaches taken attempting to solve the problem of SIDS. It would appear that major clues provided by pathological findings have been largely overlooked and as a consequence much effort, time, and money has been wasted on projects that satisfy only sub-specialty and political needs. Close examination of the pathological clues would provide better insights into the mechanisms underlying this enigmatic and heartbreaking problem.

Correspondence to: Dr P N Goldwater, Microbiology \& Infectious Diseases Department, The Women's \& Children's Hospital, North Adelaide, South Australia 5006; goldwaterp@

mail.wch.sa.gov.au

Accepted 15 March 2003
$\mathrm{T}$ he enigma of sudden infant death syndrome (SIDS) has frustrated researchers for too long. Part of the failure to determine its aetiology can be attributed to the approach. With few exceptions, this could be described as having been "flawed" since "scientific" inquiry beganaround the time when the condition ("cot death") was first defined in 1969 as "the sudden death of any infant or young child, which is unexpected by history, and which a thorough post mortem examination fails to show an adequate cause of death" ${ }^{1}$ In retrospect, it is clear that omissions of importance occurred at the time of the first and second international conferences on the causes of sudden death in infants. These omissions included appropriate consideration of the salient pathological features observed in the babies who fell under the accepted definition(s). Many articles which set out to describe the pathology of SIDS failed to do so (being incomplete) and drifted off into unjustified and fanciful supposition as to the reason for a particular finding. ${ }^{2-4}$ Why the pathological evidence was largely overlooked is hard to understand. This review will explore in detail the arguments that abounded at the time and discover why the thinking about SIDS lacked the logical and considered approach it deserved. Much of the debate has come from the two main schools of thought: (1) that SIDS has a single cause; and (2) that SIDS is an amalgam of predisposing host and epidemiological risk factors (see table 1) and is therefore multifactorial. The "single cause" school, in the main, has concentrated on single areas of interest (allergy, nutrition, metabolism, cardiological, pulmonological, neurological, endocrinological, toxicological, and infection), and with few exceptions, without much attention given to pathological clues. These approaches have been driven largely by sub-specialty and political interest rather than evidence. Likewise, the multifactorial/multiple causes school's attention to pathological information has been similarly blinkered. It is too simplistic to divide the research into these schools, for the researchers in the "single cause" school who invoke a bacterial toxin (as a likely single cause) have given due acknowledgment to the many risk factors that could play a role in SIDS. ${ }^{13-15}$ In effect, as will be revealed, a single bacterial toxin cause acting in concert with the known risk factors could be labelled as "multifactorial". Linking prone sleep position (a major risk factor) to the many other epidemiological factors has been difficult. Its relation to SIDS varies considerably in terms of relative risk. If an asphyxial mechanism is proposed to underlie an association with prone (and lateral) sleeping, the same mechanism almost certainly cannot be applied to supine sleeping, a position in which SIDS also occurs. Regrettably, there has been insufficient research and discussion in regard to supine SIDS deaths.

\section{THE PATHOLOGY OF SIDS}

Infants classified as dying from SIDS are most often normally nourished and hydrated. The nappies are usually wet and contain stool, and the bladder and rectum are typically empty. ${ }^{4}$ The salient features at post-mortem examination are the following:

\section{Liquid blood}

An early discussion on aspects of pathology that might have cleared the way to a rational approach to researching the cause SIDS took place at the Cambridge Symposium on SIDS in 1970. Liquid, unclotted blood within the chambers of the heart is a common, if not constant finding in SIDS. ${ }^{6}$ In this regard, Professor Francis Camps, doyen of forensic pathology, questioned in passing whether asphyxia could cause liquefaction of blood. He observed that asphyxiated animals have normally clotted blood and that an asphyxial mechanism could not be invoked in SIDS. $^{18}$ According to Di Maio and Di Maio, unclotted blood in the context of adult death does not infer a particular cause of death. ${ }^{19}$ Despite this, these authors claim fluidity of the blood is one of the "classical signs" of asphyxia but go on to say these signs are non-specific and can occur in deaths from other causes. The contradiction is obvious. However, in the context of sudden unexpected death in infancy (SUDI) without apparent cause, with almost every case exhibiting this finding, it would suggest a very limited number of potential causes, especially when normally clotted blood is the usual postmortem finding in infants dying suddenly 
Table 1 Predisposing host and epidemiological risk factors associated with SIDS

\begin{tabular}{l} 
Prenatal/pregnancy \\
Higher parity \\
Low birth weight, short gestation (intrauterine growth retardation) \\
Inadequate prenatal care \\
Maternal smoking \\
Smoking within the household during pregnancy \\
Maternal recreational drug use (opiates, cocaine) \\
Urinary tract infection \\
Demographic/genetic \\
Lower socioeconomic status \\
Race-ethnicity: African-American, indigenous populations: Aboriginal \\
Australian, Maori, Native Americans \\
Age at death (peak at 2-4 months) \\
Male gender \\
Cold season \\
IL-10 low producer \\
IL-1b high producers \\
Neonatal/postnatal ${ }^{56} 8$ 10-12 \\
Infections (URTI or gastroenteritis) (recent illness potentiates effect of \\
prone sleep position and overwrapping) \\
Passive exposure to cigarette smoke \\
Lack of breast feeding \\
Prone sleep position \\
Bed sharing \\
Sofa sleeping \\
Used mattress \\
Lack of or late immunisation \\
\hline
\end{tabular}

from traumatic injury and non-infective causes. Beckwith ${ }^{20}$ compared rates of completely fluid blood and partly clotted blood in SIDS and controls and showed that $92 \%$ and $7 \%$ respectively, of SIDS babies and $73 \%$ and $16 \%$, respectively of controls had the above mentioned blood states. Despite well documented information on the high frequency of unclotted blood in SIDS, some major articles on the pathology of SIDS ignore the state of the blood. ${ }^{2}$ Confounding these considerations is the observation that many cases of unquestionable asphyxia have unclotted blood. However, because there are other conditions in which liquid blood occurs, its finding does not necessarily infer asphyxia was the basis of the finding. Nevertheless, the very high frequency of demonstrable unclotted/liquid blood in SIDS should merit further investigation.

On consideration of this clue, the logical approach to investigation would be to: (1) determine whether or not perturbation of the clotting cascade underlies this phenomenon; and (2) if so, examine the origin of the perturbation, for example, endothelial cell mediated or other precipitating factor. A study that investigated disseminated intravascular coagulation (DIC) in neonatal deaths with the use of immunohistochemistry to look for fibrin related antigens (FRA) in tissues in which SIDS babies were used as a comparison group, showed minimal FRA staining, indicating DIC is an unlikely underlying mechanism in SIDS. ${ }^{21}$ Since the pathogenesis of DIC became understood in the 1960s, paediatric pathologists have been unanimous in excluding the condition on histopathological grounds. Although DIC is not part of SIDS, another mechanism must be sought to explain the phenomenon of liquid blood. Can fibrin degradation products be formed as a result of a mechanism other than DIC? It is clear that consistently higher cross linked fibrin degradation products are found frequently in SIDS sera compared with other deaths. ${ }^{22}$ This would indicate that in SIDS, a clotting perturbation has indeed occurred. Beckwith referred non-specifically to unreferenced experimental findings that "fibrinolysins are released when the heart perfuses anoxic tissues, and that they are not released when the heart stops suddenly". ${ }^{20}$ Little, if any, progress has been made on the pathogenesis of unclotted blood for more than three decades. Clues may be found in the mechanisms involved in the development of "shock lung" (acute respiratory distress syndrome) ${ }^{23}$ (vide infra) in which activation of both intrapulmonary and circulating cells occurs. ${ }^{24}$ Notably, SIDS infants have increased numbers of mast cells in lung tissue and increased levels of mast cell tryptase, ${ }^{25}$ especially in those dying prone. ${ }^{26}$ An anaphylactic reaction (involving degranulation of mast cells), could be triggered by viral infection (common in SIDS) via interferon and up-regulation of mast cell MHC II antigens-known receptors for pyrogenic toxins. ${ }^{27}$

\section{Intrathoracic petechial haemorrhages; size, number, distribution}

Much discussion has been devoted to the almost universal finding in SIDS babies of petechial haemorrhages in their intra-thoracic organs including the thymus, lungs, visceral pleura, and epicardium. Indeed, the presence of intrathoracic petechial haemorrhages is regarded by some pathologists as a prerequisite for making the diagnosis of SIDS. ${ }^{28}$ Regrettably, most studies have not attempted to delineate differences between SIDS petechiae and those found in asphyxial deaths. The few papers that have examined this have shown differences that would indicate possibly different pathogenetic mechanisms. Petechial haemorrhages were encountered in $87 \%$ of SIDS cases, but in non-SIDS cases "were mostly absent or less developed in quantitative terms". ${ }^{29}$ Others have commented along similar lines. ${ }^{30} 31$ Krouse and Jordan $^{30}$ compared the distribution of petechiae in SIDS and various other causes of death and with few exceptions, showed limitation to within the chest cavity in SIDS but extension (to below the diaphragm) in cases whose terminal course was complicated by either hypoxaemia, hypercarbia, metabolic acidosis, coagulopathy, or infection. Table 2 summarises the incidence of intrathoracic petechial haemorrhages in SIDS and non-SIDS reported by several investigators and shows impressive differences between the two groups. Beckwith ${ }^{31}$ has commented on the incidence, distribution and density of intrathoracic petechiae wherein these differences are apparent. While Prof. Camps had experience with the findings of experimental asphyxia, he was clearly unaware of the experimental findings of Handforth, ${ }^{32}$ who killed rats by tracheal occlusion and observed intrathoracic petechiae at necropsy. The observation by Beckwith that the petechiae found on the posterior side of the thymus were more numerous below than above the innominate vein in SIDS cases led to the hypothesis that the petechial distribution could be explained by the dampening effect of the vein on changes in intrathoracic pressure occurring during breathing against an occluded upper airway. ${ }^{20}$ The pathological findings derived by Valdés-Dapena and colleagues ${ }^{33}$ from the NICHHD study found petechiae in the pleura less often than most other studies. Despite this, the finding on gross pathology (54\%) was significantly greater than that in explained (nonSIDS) deaths (35\%). Gross and microscopic results combined revealed $63 \%$ of SIDS cases had pleural petechiae with only $38 \%$ of explained deaths. On comparison of frequencies of intrathoracic petechiae in this analysis, SIDS cases significantly more often had these petechiae (82\%) compared with explained deaths $(60 \%)$. There were discrepancies between observation of petechiae on gross examination compared with histopathology, with petechiae of pleura, alveoli, and septa more often noted on microscopy. Thymic petechiae were noted in $69 \%$ of SIDS cases and 38\% of explained deaths when gross and microscopic findings were combined. Had quantitative measurements of density of petechiae been undertaken in this study, further valuable comparative data 


\begin{tabular}{|c|c|c|c|}
\hline Reference & SIDS cases & $\begin{array}{l}\text { Frequency of } \\
\text { petechiae (\%) }\end{array}$ & Non-SIDS comparisons \\
\hline Werne and Garrow ${ }^{37}$ & 31 & 80 & $\begin{array}{l}\text { Absent or sparse in infant } \\
\text { suffocation, CO asphyxia, } \\
\text { drowning }\end{array}$ \\
\hline Handforth $^{32}$ & 12 & 100 & None \\
\hline Jacobsen and Voight ${ }^{38}$ & 97 & 95 & Rare in infanticide, accidents \\
\hline Geertinger $^{39}$ & 80 & 79 & 6 of $43(14 \%)$ \\
\hline Cooke and Welsh ${ }^{0}$ & 91 & 94 & $\begin{array}{l}10 \text { of } 31(32 \%) \text { in no case } \\
\text { were they numerous }\end{array}$ \\
\hline Marshall ${ }^{41}$ & 162 & 68 & 12 of $42(29 \%)$ \\
\hline Beckwith $^{31}$ & 109 & 87 & 16 of $38(42 \%)$ \\
\hline Krous $^{3}$ & 100 & 85 & None \\
\hline Valdes-Dapena et $a^{\beta 3}$ & 622 & 82 & 39 of $65(60 \%)$ \\
\hline Risse and Weiler ${ }^{29}$ & 63 (thymus) & 87 & 13 of $33(39 \%)$ (thymus) \\
\hline
\end{tabular}

would have been obtained. However, petechial haemorrhages, when present in SIDS, are much denser (in number per area) than in non-SIDS deaths. ${ }^{3}$ Given that the NICHHD study ${ }^{33}$ purported to be broad and encompassing all things pathological in SIDS, it is disappointing that quantitative and qualitative analysis of petechiae was not undertaken and organ weights (see below) were not analysed.

Byard and Krous ${ }^{34}$ relegated petechial haemorrhages to "minor" pathological findings yet they declare these are well recognised in cases of SIDS and occur in $68-95 \%$ of cases and may be caused by the mechanisms that led to the terminal event. ${ }^{35}$ Furthermore, the authors contrast the findings seen in cases of hanging and crush asphyxia in which petechiae of the conjunctiva and face-findings unusual in infants dying of other causes (that is, SIDS). They quote Dr John Hilton ${ }^{36}$ that petechiae "are never present on the conjunctiva, eyelids or on or in other soft tissues of the head or neck in SIDS". Byard and Krous $^{34}$ support the contention that finding petechiae on the face, neck, upper chest, or conjunctivae warrants suspicion and extremely careful investigation. It has been presumed, but by no means proven, that intrathoracic petechiae in SIDS are the consequence of breathing against an occluded upper airway. Just where the alleged obstruction is thought to occur has never been established. Nor have other causes of petechial haemorrhage been vigorously sought. Potential avenues of research that have been largely overlooked include the clotting cascade, toxic or immunological damage to the capillary basement membrane or other molecular events taking place during toxic or septic shock.

In summary, while intrathoracic petechial haemorrhages are extremely common in SIDS they are a non-specific finding; however, the predictive value of finding petechiae has never been explored (vide infra). Notwithstanding this, there has been an almost total absence of research into mechanisms by which petechiae form (other than a respiratory one).

\section{Fluid-laden, congested organs}

The weights of the thymus, lungs, liver, and brain appear to be significantly greater in SIDS cases than published norms. ${ }^{42}$ The study by Siebert and Haas ${ }^{42}$ analysed data from 500 postmortem examinations performed over 15 years by one pathologist. It is understandable that so-called "normal" weights tend to be low as a result of underlying disease in this comparison group. Nevertheless, it is clear that in SIDS the above mentioned organs are fluid laden and thus heavy. ${ }^{42}$ The underlying pathophysiological processes have not been the subject of investigation.

\section{Brain}

To quote Kinney and Filiano, ${ }^{43}$ "Of all neuropathologic findings, heavy brain weight is perhaps the best established, because of the simplicity and reproducibility of the method of measurement, i.e. weighing the unfixed brain at autopsy." The underlying cause of the increased brain weight would include the following possibilities: cerebral oedema (secondary to hypoxia/anoxia or toxic/metabolic factors), agonal vascular congestion, or megalencephaly. However, no investigation into mechanisms by which the phenomenon of heavy brain weight in SIDS occurs has been adequately studied. One exception is the identification of staphylococcal toxins in various tissues (including brain) of SIDS babies, ${ }^{44}$ thus suggesting a toxic cause of brain swelling.

To link the pathological finding of heavy brain weight to prone sleep position and other epidemiological features requires a special exercise of imagination. One such exercise has resulted in the "triple risk" model encompassing vulnerability, a critical development period and exogenous stressors. ${ }^{43}$ This is fine when applied to the epidemiological findings in SIDS but becomes convoluted, complex, and implausible when a link with prone sleep position is attempted. It may not be a coincidence that periventricular leukomalacia, a characteristic finding in babies who develop cerebral palsy, is also common in SIDS.45 ${ }^{46}$ Many of the epidemiological features of SIDS are shared with those of cerebral palsy. Not only is the incidence of cerebral palsy similar to SIDS (2-2.5 cases per 1000 live births), but many risk factors for the occurrence of cerebral palsy are shared with SIDS, including maternal age, maternal infection, multiple births, shorter gestational age, and low birth weight. $^{47-49}$ The list of neurohistopathological changes claimed to be associated with SIDS is long, and with the use of conventional techniques SIDS brains look normal or have inconsistent minor changes such as mild brain stem gliosis. ${ }^{43}$ The studies are frequently contradictory. ${ }^{43}$

\section{Thymus}

As mentioned, thymus weights tend to be heavier in SIDS cases than in "normal" babies. Again the comparison (normal) group may have had underlying disease that could have impacted on the health of the thymus and therefore the organ's weight. No data exist that correlate the thymus weights with the density of petechial haemorrhages.

\section{Lungs}

Heavy, fluid laden lungs in SIDS is a frequent, if not invariable finding. Although asphyxia is described as one of the conditions in which fluid laden lungs occur, other 
potential explanations have never been adequately addressed, especially from the point of view of blood vessel basement membrane integrity. "Shock lung" is a condition in which perturbation of the inflammatory pathways leads to damage of capillary basement membranes and leakage of fluid into the alveolae and interstitium. ${ }^{23}$ Non-asphyxial explanations deserve appropriate investigation. Intra-alveolar haemorrhage would contribute to lung heaviness. The causes of intra-alveolar haemorrhage are many and varied and have been widely debated; however, pathologists are wary of the possibility of mechanical asphyxia when more than 5\% of alveolar area is occupied by red blood cells, but appropriate studies have not been conducted to provide definitive data. ${ }^{50}$ Others have examined semiquantitative morphological determinants of asphyxia in lung tissue ${ }^{51}$ and showed good correlation with the types of asphyxia (for example, foreign body, suffocation, drowning and strangulation) but did not examine lungs from SIDS cases. Potentially valuable findings could be forthcoming if similar methodology were to be used in the context of SIDS.

\section{Liver}

Fatty change is described in SIDS, but the finding is variable and therefore cannot adequately explain the increase in weight of SIDS babies' livers over comparison babies. Again the mechanism by which the liver becomes heavy in SIDS needs addressing.

\section{PREDICTIVE VALUE OF SPECIFIC PATHOLOGICAL FINDINGS}

To my knowledge, no effort has been made to determine the predictive value of a particular pathological finding in helping to reach a diagnosis or exclude a diagnosis of SIDS. For instance, what is the predictive value of thymic petechiae of a particular density, or pleural or cardiac petechiae at a particular age? Or, what is the predictive value of an organ weight at a particular age? Examination of the data from the NIHCHD study provides some insights. For instance, the predictive value of finding thymic petechiae (gross and/or microscopic examination) would be $95.5 \%$ predictive of SIDS; the absence of petechiae would give a predictive value of $14.8 \%$. In the case of intrathoracic petechiae the predictive value of such a finding is equally high at $94.1 \%$ and the predictive value of their absence would be $16.1 \%$.

\section{Inflammatory infiltrates}

Inflammatory changes in the respiratory epithelium is a common finding in SIDS and probably reflects recent viral respiratory symptoms noted in up to $44 \%$ of cases within the last two weeks of life..$^{52}$ The degree of inflammation in the trachea and bronchioles observed in SIDS is considered inadequate to represent a cause of death..$^{53}$ Nevertheless, a contributory role of virus infection in SIDS through viral potentiation of bacterial toxins remains a possibility (vide infra). ${ }^{54}$

\section{Bacterial toxins, viral infection, smoke}

Blackwell and colleagues ${ }^{13}$ have given due prominence and summarised a microbiological perspective of SIDS, but the focus was mainly on staphylococcal toxins. Independent studies have shown an increased colonisation rate by toxigenic bacteria in the gut of babies who have died of SIDS compared with healthy living babies or babies who died of other causes. ${ }^{13-16}$

Other studies have shown nasopharyngeal colonisation by Escherichia coli ${ }^{55} 56$ and Staphylococcus aureus, ${ }^{56}$ with increased colonisation of the latter in infants who slept prone. ${ }^{56}$ Furthermore, if toxins were involved in SIDS causation, these should be demonstrable in the sera of SIDS cases. Indeed the lethal toxicity of serum from SIDS babies compared to controls has been shown by Alexander and colleagues $^{57}$ in infant mice and by Sayers and colleagues ${ }^{58}$ in chick embryos. Notably in both studies the sera from control infants were non-lethal. In addition, $E$ coli strains isolated from SIDS babies (but not healthy babies) are lethal to mice. ${ }^{59}$ This work failed to show known $E$ coli toxins (for example, ST, LT, stx) in most SIDS cases and was thus a stimulus to seek new toxic bacterial proteins; this led to the discovery of soluble curlin in all SIDS sera of an Australia series examined. ${ }^{60}$ This finding awaits independent validation.

Generally not appreciated is the fact that bacterial protein toxins are potentiated (that is, made more lethal) with coexistent viral infection ${ }^{546162}$ and/or exposure to smoke. ${ }^{6364}$ The latter two factors belong in the list of risk factors for SIDS. It is noteworthy that bacterial toxins potentiate each other, ${ }^{65}$ indicating a potential role for multiple toxin (staphylococcal, E coli, clostridial) involvement in SIDS.

\section{PRONE SLEEPING POSITION AND THE CHANGING PREVALENCE OF SIDS}

The "reducing the risk" and "back to sleep" campaigns were based on epidemiological findings from several studies in relation to prone sleep position. ${ }^{66}$ The campaigns perpetuate a biased approach to this enigmatic and important cause of post-neonatal death. Although since 1991 the rate of SIDS seems to have fallen by about $50 \%$ in a number of countries, SIDS remains a major contributor to post-neonatal mortality and SIDS incidence varies considerably geographically. ${ }^{67}$ Notwithstanding the possible influence of inconsistent autopsy protocols and criteria for SIDS diagnosis, this apparent fall may only be a reflection of natural variation. This idea is supported by Swedish figures, showing that the rate in the late 1990s has returned to the level observed in the early 1970s. The decline seen in the early 1990s began before the introduction of the "back to sleep" campaign. ${ }^{68}$ Australian data are similar to those of Sweden but do not go back as far. In support of the phenomenon of natural variation in rates of SIDS is the observed upswing in Victorian SIDS numbers in 2002 (Victorian Institute of Forensic Medicine data). This may herald a return to the disturbing figures observed in the 1980s and 1990s. If the current practice of avoiding prone sleep position sustains, reappraisal of sleep position in relation to a rising SIDS incidence will be necessary.

As mentioned above, mechanisms culminating in asphyxia $^{69}$ cannot provide the answer to SIDS because the findings in asphyxial death fly in the face of pathological evidence; especially in regard to the number and distribution of petechiae, not to mention organ weight information. Cases of SIDS captured on 24 hour computerised memory monitors (tracing pulse, respiratory rate, and blood pressure) also show asphyxia was an impossibility. ${ }^{70}{ }^{71}$ Invoking an asphyxial mechanism for prone position must logically exclude the same mechanism for most deaths in supine and lateral positions.

The effect of prone sleep position could hypothetically be explained on the basis of: (1) greater chance of ingestion of bacteria contaminating the sleeping surface, ${ }^{72}{ }^{73}(2)$ induction of temperature dependent bacterial toxins, ${ }^{74}$ and (3) possible differences in rates of delivery to the systemic circulation of gut derived lethal toxin..$^{75}$

A candidate "toxin" is soluble curlin antigen, CsgA (the subunit of curli fimbriae-a colonisation/adherence factor common to most Enterobacteriaceae), accompanied (or not) by other toxins absorbed through the gut reaching the circulation via the portal system which takes it to the liver. Fatty change (for which toxaemia is a cause) is found in the livers of some SIDS babies. ${ }^{17} 77$ A second, possibly more 
important route of curlin/toxin absorption, would be via the lymphatic system and the thoracic duct. Curlin protein/toxin would be delivered via the duct to the innominate vein and thence to the right side of the heart. The first organ exposed to curlin would be the lungs followed by the heart and the thymus. These are the organs in which classical pathological findings in SIDS are seen (petechiae, and wet/heavy lungs). Bacterial toxins/products can perturb basement membranes of small blood vessels leading to the small haemorrhages (petechiae) and fluid laden organs seen in SIDS. Curlin binds to fibronectin ${ }^{78}$ and this could precipitate damage to capillary basement membranes and perturb the clotting system. The pattern of distribution of petechiae is distinctive and could be explained by the fact that these would be the first organs exposed (as explained above) or that these organs are replete with toxin receptors. ${ }^{75} 76$ This hypothesis explains why more deaths occur in the prone position in which a lethal amount of toxin is delivered; and in other positions, by inference, a usually sublethal dose is delivered to the systemic circulation. Paracelsus' notion ${ }^{79}$ that "the dose makes the poison" predated our understanding of minimal lethal dose or LD50. The above mentioned pathological findings in SIDS include:

- Liquid (unclotted) blood within the chambers of the heart, ${ }^{17}{ }^{20}$ and increased cross linked fibrin degradation products $^{22}$ (seen in toxaemia/sepsis); in this context, curlin protein represents contact phase bacterial components which can activate the proinflammatory pathway, ${ }^{80} 81$ involving reactions with fibrinogen and fibronectin ${ }^{82}$ which can lead to depletion of coagulation factors resulting in a hypocoagulability state. ${ }^{22}$

- The finding of an empty bladder in most SIDS cases ${ }^{17} 77$ suggests decreased renal perfusion (toxaemic shock) during the last sleep. Thus this proposed hypotension could be explained by curlin protein induction of proinflammatory cytokines with release of bradykinin and/or $\mathrm{NO}^{83}$

The link between infection, inflammation, and the risk factors for SIDS has been expressed similarly by Blackwell and colleagues. ${ }^{84}$ The role of endotoxin seems in doubt, which simplifies the search for a more specific toxin candidate. A number of studies have been unable to ascertain the presence of endotoxin in amounts different from controls. ${ }^{85}$ Disseminated intravascular coagulation (DIC) would be an expected finding if endotoxin were involved to any great extent. The absence of DIC in SIDS supports this.

\section{FUTURE RESEARCH}

It is time to address the deficiencies in direction and funding of SIDS research. Many unresolved issues need clarification: Clues including susceptibility to infection need to be addressed by examining several aspects of the innate immune system which would likely play an important role through induction of adverse reactions to infection in infancy. Examination of polymorphisms for mannose-binding lectin, and pro- and anti-inflammatory cytokines might provide insights into differences in incidence of SIDS among different ethnic groups. Energy should go into independent confirmation of the findings in relation to soluble curlin-a candidate toxin that seems to fulfil the necessary attributes of a causal agent. Development of models of infection in the susceptible host must also be attempted to provide a better understanding of the mechanism(s) involved in SIDS. There is a need to reassess the suspected "red herrings" of brain stem astrocytosis, pulmonary haemosiderin, mycotoxins, organophosphates, and similar ideas with poor correlations with SIDS. If SIDS research funding organisations are serious about finding a solution to SIDS it would be helpful if they could reassess their directions and philosophical approach.

\section{REFERENCES}

1 Bergman AB, Beckwith JB, Ray CG, eds. Sudden infant death syndromeProceedings of the Second International Conference on Causes of Sudden Death in Infants. Seattle: University of Washington Press, 1970.

2 Rognum TO. Definition and pathologic features. In: Byard RW, Krouse HF, eds. Sudden infant death syndrome: problems, progress and possibilities. London: Arnold, 2001:4-30.

3 Krous HF. The microscopic distribution of intrathoracic petechiae in sudden infant death syndrome. Arch Pathol Lab Med 1984:108:77-9.

4 Krous HF. Pathological considerations of sudden infant death syndrome. Int J Child Adolesc Health 1988;15:231-9.

5 Willinger M. SIDS-a challenge. J Natl Inst Health Res 1989;1:73-80.

6 Valdes-Dapena MA. Sudden infant death syndrome: a review of the medical literature 1974-1979. Pediatrics 1980;66:597-614.

7 Standfast SJ, Jereb S, Janerich DT. The epidemiology of sudden infant death in upstate New York: II: Birth characteristics. Am J Public Health 1980;70:1061-7.

8 Hauk FR. Changing epidemiology. In: Byard RW, Krouse HF, eds. Sudden infant death syndrome: problems, progress and possibilities. London: Arnold, 2001:31-57.

9 Gardner A. Urinary tract infections during pregnancy and sudden unexpected infant death [letter]. Lancet 1985:2:495.

10 Hoffman HJ, Hillman LS. Epidemiology of the sudden infant death syndrome: maternal, neonatal and postneonatal risk factors [review]. Clin Perinatol 1992;19:717-37.

11 Platt MW, Blair PS, Fleming PJ, et al. A clinical comparison of SIDS and explained sudden deaths: how healthy and how normal? Arch Dis Child 2000;82:98-106

12 Gilbert RE, Wigfield RE, Fleming PJ, et al. Bottle feeding and the sudden infant death syndrome. BMJ 1995;310:88-90.

13 Blackwell CC, Weir DM, Busuttil A. A microbiological perspective. In: Byard RW, Krouse HF, eds. Sudden infant death syndrome: problems, progress and possibilities. London: Arnold, 2001:182-208.

14 Bettelheim KA, Goldwater PN, Dwyer BW, et al. Toxigenic Escherichia coli associated with sudden infant death syndrome. Scand J Infect Dis 1990;22:467-76.

15 Murrell WG, Stewart BJ, O'Neill C, et al. Enterotoxigenic bacteria in the sudden infant death syndrome. J Med Microbiol 1993;39:1 14-27.

16 Bettiol SS, Radcliffe FJ, Hunt ALC, et al. Bacterial flora of Tasmanian SIDS infants with special reference to pathogenic strains of Escherichia coli. Epidemiol Infect 1994;112:275-84.

17 Williams AL. Sudden infant death syndrome. Aust N Z J Obstet Gynaecol 1990;30:98-107.

18 Camps FE. Sudden and unexpected deaths in infancy (cot deaths). In: Report of the Proceedings of the Sir Samuel Bedson Symposium, Cambridge. April 1970. Bristol: John Wright \& Sons, 1972:50.

19 Di Maio DJ, Di Maio VJM, eds. Forensic pathology. New York: Elsevier, 1989:207.

20 Beckwith JB. Observations of the pathological anatomy of the sudden infant death syndrome. In: Bergman AB, Beckwith JB, Ray CG, eds. Sudden infant death syndrome. Proceedings of the second International Conference on Causes of Sudden Death in Infants. Seattle: University of Washington Press, 1970:132.

21 Conover PT, Abramowsky C, Beyer-Patterson P. Immunohistochemical diagnosis of disseminated intravascular coagulation in newborns. Pediatr Pathol 1990; 10:707-16.

22 Goldwater PN, Williams $\vee$, Bourne AJ, et al. Sudden infant death syndrome: a possible clue to causation. Med J Aust 1990;153:59-60.

23 Kollef MH, Schuster DP. Acute respiratory distress syndrome. N Engl J Med 1995;332:27-37.

24 Hamcher J, Lucas R, Lijnen HR, et al. Tumor necrosis factor- $\alpha$ and angiotensin are mediators of endothelial cytotoxicity in bronchoalveolar lavages of patients with acute respiratory distress syndrome. Am J Respir Crit Care Med 2002; 166:651-6

25 Holdgate ST, Walters C, Walls AF, et al. The anaphylaxis hypothesis of sudden infant death syndrome (SIDS): mast cell degranulation in cot death revealed by elevated concentrations of tryptase in serum. Clin Exp Allergy 1994;23:115-23.

26 Edston E, Gidlund E, Wickman $M$, et al. Increased mast cell tryptase in sudden infant death-anaphylaxis, hypoxia or artefact? Clin Exp Allergy 1999:29: 1648-54

27 Dimitriadou V, Mecheri S, Koutsilieris $M$, et al. Expression of functional major histocompatibility complex class II molecules on HMC-1 human mast cells. $J$ Leukoc Biol 1998;64:791-9.

28 Haas JE, Taylor JA, Bergman AB, et al. Relationship between epidemiologic risk factors and clinicopathologic findings in SIDS. Pediatrics 1993:91:106-12.

29 Risse M, Weiler G. Differential diagnosis SIDS/non-SIDS on the basis of histological findings of petechial thymus hemorrhages. Forensic Sci Int 1989.43:1-7.

30 Krouse HF, Jordan J. A necropsy study of the distribution of petechiae in nonsudden infant death syndrome. Arch Pathol Lab Med 1984;108:75-6.

31 Beckwith JB. Intrathoracic petechial hemorrhages: a clue to the mechanism of death in sudden infant death syndrome. Ann NY Acad Sci 1988;533:37-47.

32 Handforth PC. Sudden unexpected death in infants. Can Med Assoc J $1959: 80: 872-3$. 
33 Valdés-Dapena M, McFeeley PA, Hoffman HJ, et al. Summary of histopathologic findings and implications for future SIDS research. In Histopathology atlas for sudden infant death syndrome. Washington, DC Armed Forces Institute of Pathology, American Registry of Pathology \& The National Institute of Child Health and Human Development, 1993:281-99.

34 Byard RW, Krous HF. Specific pathologic problems and possible solutions. In: Byard RW, Krouse HF, eds. Sudden infant death syndrome: problems, progress and possibilities. London: Arnold, 2001:230-1.

35 Beckwith JB. The mechanism of death in sudden infant death syndrome. In: Culbertson JL, Krouse HF, Bendell RD, eds. Sudden infant death syndrome: medical and psychological management. London: Edward Arnold, 1989:48-61

36 Hilton JMN. The pathology of sudden infant death syndrome. In: Mason JK ed. Paediatric forensic medicine and pathology. London: Chapman \& Hall Medical, 1989:156-64

37 Werne J, Garrow I. Sudden apparently unexplained death during infancy. 1 Pathologic findings in infants found dead. Am J Pathol 1953;29:633-52

38 Jacobsen T, Voight J. Sudden and unexpected infant death. II. Result of medico-legal autopsies of 356 infants aged 0-2 years. Acta Med Leg Soc (Liege) 1956;9:133-59

39 Geertinger P. Sudden death in infancy. Springfield, IL: Charles C. Thomas, 1968.

40 Cooke RT, Welsh RG. A study in cot death. BMJ 1964;2:1549-54.

41 Marshall TK. The Northern Ireland study: pathology findings. In: Bergman AB, Beckwith JB, Ray CG, eds. Sudden infant death syndrome. Proceedings of the Second International Conference on Causes of Sudden Death in Infants. Seattle: University of Washington Press, 1970:108-17.

42 Siebert JR, Haas JE. Organ weights in sudden infant death syndrome. Pediatr Pathol 1994; 14:973-85.

43 Kinney HC, Filiano JJ. Brain research in sudden infant death syndrome. In: Byard RW, Krouse HF, eds. Sudden infant death syndrome: problems, progress and possibilities. London: Arnold, 2001:118-37.

44 Blackwell CC, Gordon AE, James VS, et al. The role of bacterial toxins in sudden infant death syndrome (SIDS). Int J Med Microbiol 2002;291:561-70.

45 Kinney HC, Brody BA, Finkelstein DM, et al. Delayed central nervous system demyelination in the sudden infant death syndrome. J Neuropathol Exp Neurol 1991;50:29-48.

46 Takashima S, Armstrong D, Becker LE, et al. Cerebral white matter lesions in the sudden infant death syndrome. Pediatrics 1978:62:155-9.

47 Goldenberg R, Nelson K. Cerebral palsy. In: Creasy R, Resnik R, eds. Maternal-fetal medicine, 4th edn. Toronto: WB Saunders, 1999:1194-214.

48 Grether JK, Nelson KB. Maternal infection and cerebral palsy in infants of normal birth weight. JAMA 1997;278:207-11

49 Nelson KB, Grether JK. Causes of cerebral palsy. Curr Opin Pediatr 1999; 11:487-91.

50 Berry PJ. Intra-alveolar haemorrhage in sudden infant death syndrome: a cause for concern? J Clin Pathol 1999:52:553-4.

51 Delmonte C, Capelozzi VL. Morphologic determinants of asphyxia in lungs: a semiquantitative study in forensic autopsies. Am J Forensic Med Pathol 2001;22:139-49.

52 Hoffman HJ, Damus K, Hillman L, et al. Risk factors for SIDS: results of the National Institute of Child Health and Human Development SIDS Cooperative Epideiological Study. Ann N Y Acad Sci 1988;533:13-30.

53 Cutz E, Jackson A. Airway inflammation and peripheral chemoreceptors. In: Byard RW, Krouse HF, eds. Sudden infant death syndrome: problems, progress and possibilities. London: Arnold, 2001:156-81.

54 Jakeman KJ, Rushton DI, Smith H, et al. Exacerbation of bacterial toxicity to infant ferrets by influenza virus: possible role in sudden infant death syndrome. J Infect Dis 1991;163:35-40.

55 Pearce J, Luke RK, Bettelheim KA. Extraintestinal Escherichia coli isolations from SIDS cases and other cases of sudden death in Victoria, Australia. FEMS Immunol Med Microbiol 1999;25:137-44.

56 Harrison LM, Morris JA, Telford DR, et al. The nasopharyngeal flora in infancy: effects of age, gender, season, viral upper respiratory tract infection and sleeping position. FEMS Immunol Med Microbiol 1999;25:19-28.

57 Alexander R, Bettelheim KA, Cairney PC, et al. Microbiological investigations of suspected sudden infant death syndrome (SIDS) cases. Aust Microbiol 1987:8:156, (abstract P4.6)

58 Sayers NM, Drucker DB, Hutchinson IV, et al. Preliminary investigation of lethally toxic sera of sudden infant death syndrome victims and neutralisation by commercially available immunoglobulins and adult sera. FEMS Immunol Med Microbiol 1999;25:193-8.

59 Bettelheim KA, Pearce JL, Evangelidis $\mathrm{H}$, et al. A mouse model for sudden infant death syndrome. Proceedings of the 2nd SIDS Family International Conference, Sydney, 1992. Ithaca, NY: Perinatology Press, 1993:121-3.

60 Goldwater PN, Bettelheim KA. Curliated Escherichia coli, soluble curlin and the sudden infant death syndrome (SIDS). J Med Microbiol 2002;51:1009-12

61 Mach AM Lindsay JA. Activation of Clostridium perfringens cytotoxic enterotoxin(s) in vivo and in vitro: role of triggers for sudden infant death. Curr Microbiol 1994;28:261-7.

62 Sarawar SR, Blackman MA, Doherty PC. Superantigen shock in mice with an inapparent viral infection. J Infect Dis 1994;170:1 189-94.

63 Sayers NM, Drucker DB, Telford DR, et al. Effects of nicotine on bacterial toxins associated with cot death. Arch Dis Child 1995:73:549-51.

64 Sayers NM, Drucker DB. Animal models used to test the interactions between infectious agents and products of cigarette smoked implicated in sudden infant death syndrome. FEMS Immunol Med Microbiol 1999;25:115-23.

65 Drucker DB, Aluyi HS, Morris JA, et al. Lethal synergistic action of toxins of bacteria isolated from sudden infant death syndrome. J Clin Pathol 1992;45:799-801

66 Mitchell EA. SIDS: facts and controversies. Med J Aust 2000;173:175-6.

67 Beal SM, Finch CF. An overview of retrospective case-control studies investigating the relationship between prone sleeping position and SIDS. J Paediatr Child Health 1991;27:334-9.

68 Alm B, Norvenius SG, Wennergren G, et al. Changes in the epidemiology of sudden infant death syndrome in Sweden 1973-1996. Arch Dis Child 2001;84:24-30.

69 Galland BC, Taylor BJ, Bolton DPG. Review article. Prone versus supine sleep position: a review of the physiological studies in SIDS research. J Paediatr Child Health 2002;38:332-8.

70 Kelly DH, Pathak A, Meny R. Sudden bradycardia in infancy. Pediatr Pulmonol 1991:10:199-204.

71 Poets CF, Meny RG, Chobanian MR, et al. Gasping and other cardiorespiratory patterns during sudden infant deaths. Pediatr Res 1999;45:350-4.

72 Tappin D, Brooke H, Ecob R, et al. Used infant mattresses and sudden infan death syndrome in Scotland: case-control study. BMJ 2002;325:1007-12.

73 Blackwell CC, Weir DM, Bussuttil A. Risk factors for cot death increase danger of infection: association between used mattresses and cot deaths is multifactorial. BMJ 2003:326:222

74 Molony N, Blackwell CC, Busuttil A. The effect of prone posture on nasal temperature in children in relation to induction of staphylococcal toxins implicated in sudden infant death syndrome. FEMS Immunol Med Microbiol 1999;25:109-13.

75 Goldwater PN. Reappraisal of the SIDS enigma: an epidemiological and clinicopathological approach. J Paediatr Child Health 1992;(suppl 1):S21-5.

76 Goldwater PN. SIDS: more facts and controversies. Med J Aust 2001;174:302-4

77 Valdes-Dapena $M$. The pathologist and the sudden infant death syndrome. Am J Pathol 1982;106:118-31.

78 Olsen A, Jonsson A, Normark S. Fibronectin binding mediated by a novel class of surface organelles on Escherichia coli. Nature 1989;338:652-5.

$79 \mathrm{http}: / /$ www.academicpress.com/pesttox/pdf/krieger_HPT2_foreward.pdf.

80 Bian Z, Yan ZQ, Hansson GK, et al. Activation of inducible nitric oxide synthetase/nitric oxide by curli fibres leads to a fall in blood pressure during systemic Escherichia coli infection in mice. J Infect Dis 2001;183:612-19.

81 Bian Z, Brauner A, Li Y, et al. Expression of and cytokine activation by Escherichia coli curli fibers in human sepsis. J Infect Dis 2000;181:602-12.

82 Herwald H, Mörgelin M, Olsen A, et al. Activation of the contact phase system on bacterial surfaces - a clue to serious complications in infectious diseases. Nature Medicine 1998;4:298-302.

83 Bian Z, Yan ZQ, Hansson GK, et al. Activation of inducible nitric oxide synthetase/nitric oxide by curli fibres leads to a fall in blood pressure during systemic Escherichia coli infection in mice. J Infect Dis 2001:183:612-19.

84 Blackwell CC, Gordon AE, James VS, et al. Making sense of the risk factors for sudden infant death syndrome (SIDS): infection and inflammation. Rev Med Microbiol 2001;12:219-29.

85 Crawley BA, Morris JA, Drucker DB et al. Endotoxin in blood and tissue in the sudden infant death syndrome. FEMS Immunol Med Microbiol 1999:25:131-5 